\title{
Effects of biotic and abiotic factors on soil organic carbon in semi-arid grassland
}

\author{
Fu-Ping Tian ${ }^{1}$, Zhi-Nan Zhang ${ }^{2}$, Xiao-Feng Chang ${ }^{1,2}$, Lei Sun ${ }^{3}$, Xue-Hong Wei ${ }^{3}$, Gao-Lin \\ $\mathrm{Wu}^{2,3^{*}}$
}

${ }^{1}$ Lanzhou Scientific Observation and Experiment Field Station of Ministry of Agriculture for Ecological System in the Loess Plateau Area, Lanzhou Institute of Animal and Veterinary Pharmaceutics Sciences, Chinese Academy of Agricultural Sciences, Lanzhou, Gansu 730050, China. ${ }^{2}$ State Key Laboratory of Soil Erosion and Dryland Farming on the Loess Plateau, Institute of Soil and Water Conservation, Chinese Academy of Sciences and Ministry of Water Resources, Yangling, Shaanxi 712100, China. ${ }^{3}$ Agricultural and Animal Husbandry College of Tibet University, Nyingchi 860000,China *Corresponding author: gaolinwu@gmail.com

\begin{abstract}
Carbon sequestration in grassland soil has been paid considerable attention in recent decades. However, the changes of soil organic carbon (SOC) still need clarification under the effect of environmental factors in semiarid area. Here, twenty sampling sites were selected to study the effects of plant community (plant cover, biomass, litter, composition and diversity) and environmental factors (i.e. mean annual precipitation, mean annual temperature) on SOC sequestration in the semi-arid grasslands. The results showed that SOC was significant positively related to mean annual precipitation, soil water content and soil $\mathrm{pH}$. The higher aboveand below-ground biomass, species evenness and diversity presented the higher SOC. Specially, the species richness and proportion of gramineous species functional group significantly increased SOC. Below-ground biomass affected SOC mainly in the top $30 \mathrm{~cm}$ soil. Our results suggest that higher plant species richness and gramineous species proportion play a positive role in increasing the potential of soil carbon sequestration in semi-arid grassland.
\end{abstract}

\section{Introduction}

Soil carbon $(\mathrm{C})$ is the largest $\mathrm{C}$ pool in terrestrial biosphere, which stored more $\mathrm{C}$ than that contained in plants and the atmosphere (Jobbágy and Jackson, 2000). Even a slight change in the amount of soil C may dramatically influence atmospheric $\mathrm{CO}_{2}$ concen- tration. Thus, soil carbon pays a critical role in global C cycling (Shi et al., 2012; Song et al., 2012). The climate change could profoundly affect vegetation, soil and the carbon cycle of terrestrial ecosystem (Jobbágy and Jackson, 2000). 
As the important form of human managing and utilizing grassland, cultivation and abandonment significantly affected soil organic carbon cycles (Shang et al., 2012; 2014). So it is necessary to determine more effective strategies for land use and vegetation management to ameliorate the rising level of atmospheric CO2 (Yang et al., 2015).

Changes in environmental factors can greatly affect $\mathrm{C}$ and nitrogen $(\mathrm{N})$ cycling in terrestrial ecosystems (Allison and Treseder, 2008; Liu et al., 2009). Previous studies have documented that soil organic carbon (SOC) content would increase or stay constant with precipitation change (Song et al., 2012; Zhou et al., 2009). Grassland represents an important global C reservoir, and stores as much as $20 \%$ of global soil C (Jobbágy and Jackson, 2000). Thus, the changes of soil $\mathrm{C}$ in grassland will be a significant component of the global soil $\mathrm{C}$ feedback to plant and climate change (Jobbágy and Jackson, 2000; Song et al., 2012). However, there were few field experimental evidences on the responses of SOC to community composition and abiotic factors in the natural grassland (Fornara and Tilman, 2008).

Plant-soil feedbacks play an important role in the maintenance of both plant community structures and soil properties (Bezemer et al., 2006). Changes in plant composition can alter soil organic matter, soil nutrient availability, and the composition of soil microbial communities (Casper and Castelli, 2007; Fornara and Tilman, 2008; Shang et al., 2014). These influences on soil chemical properties result in either net positive or negative effects, associated with plant performance and plant community composition (Kardol et al., 2006; Wu et al., 2016). Additionally, some previous studies found that climate change influenced plant growth and soil microbial activities (Bai et al., 2010; Song et al., 2012). However, these studies only focus on one or two aspects among climate change, plant and soil property. As the best of our knowledge, the relationships between plant community and soil property under the condition of climate change are still poorly understood. So it is significant for us to understand the relationship among the three factors, which contribute to the ecological systems.

The Chinese government has implemented the most ambitious ecological program titled 'Grain-forGreen' project (converting degraded, marginal land and cropland into grassland, shrubland and forest). The large scale of project can enhance $\mathrm{C}$ sequestration capacity in China, especially in arid and semiarid areas. Our aims are offering a new perspective in the study of SOC response to plant-soil interface microhabitats (biotic and abiotic factors) in semiarid grassland.

The specific objectives of this study are that (1) to find the role of (biotic and abiotic factors on SOC in the plant-soil interface microhabitats; (2) understanding the relationship between plant community composition and abiotic factors and SOC in typical semi-arid temperate grasslands

\section{Materials and Methods}

\subsection{Study area}

This study was conducted at Gansu Province, China. The region is characterized by semi-arid climate, mean annual temperature (MAT) ranges from 6.73 to 9.57 ${ }^{\circ} \mathrm{C}$ and mean annual precipitation (MAP) ranges from 183.81 to $387.77 \mathrm{~mm}$. $75 \%$ of the annual rainfall in this region is concentrated in July-September. We selected 20 sites (longitude $103^{\circ} 24^{\prime}$ ' $-54^{\prime} \mathrm{E}$, latitude $35^{\circ} 15^{\prime}-22^{\prime} \mathrm{N}$, and altitude from 1434 to $2523 \mathrm{~m}$ ) (Figure 1) for soil and plant community sampling (Wu et al., 2014), and the soil $\mathrm{pH}$ value ranges from 7.70 to 9.06. The main species in study sites include Labiatae (Thymus mongolicus), Gramineae (Stipa bungeana, Stipa grandis and Agropyron cristatum), Compositae 
(Heteropappus altaicus, Artemisia gmelinii, Artemisia ordosica, Artemisia frigida and Peganum multisectum).

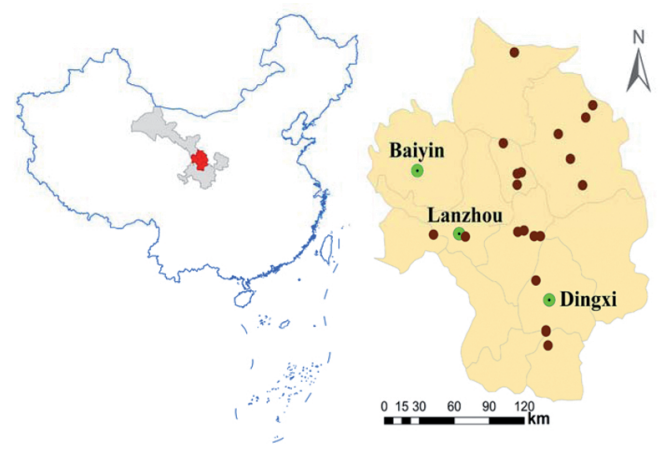

Figure 1. Location of sampling sites used in this study.

\subsection{Experimental design}

At each site, one plot $(20 \mathrm{~m} \times 20 \mathrm{~m})$ was set up randomly. Ten quadrats $(1 \mathrm{~m} \times 1 \mathrm{~m})$ were emplaced in diagonal line for community survey. Five plots were chosen to harvest all plants (above-ground biomass (AGB) and litter), the other five plots were collected plant species (plant cover, name, height, number). Three samples were taken with a $9 \mathrm{~cm}$ diameter corer to sample belowground biomass at a soil depth of $0-10,10-20,20-30,30-50,50-70$ and 70-100 cm in each quadrat. The samples in same layers were mixed together to make one sample. The majority of the roots were found in the soil samples thus obtained and then isolated using a $2 \mathrm{~mm}$ sieve. The remaining fine roots taken from the soil samples were isolated by spreading the samples in shallow trays, overfilling the trays with water and allowing the outflow from the trays to pass through a $0.5 \mathrm{~mm}$ mesh sieve. All the isolated roots were oven-dried at $65{ }^{\circ} \mathrm{C}$ and weighed to within $0.01 \mathrm{~g}$. Five replicate (four corners and center of the quadrat) soil samples were taken with a 6 $\mathrm{cm}$ diameter soil corer, and the depths were consistent with belowground biomass. All soil samples were airdried and then passed through a $2 \mathrm{~mm}$ sieve. The soil bulk density $\left(\mathrm{g} \mathrm{cm}^{-3}\right)$ was measured using a soil bulk sampler with a $5-\mathrm{cm}$ diameter and 5-cm high stainless steel cutting ring. The original volume of each soil core and its dry mass after oven-drying at $105^{\circ} \mathrm{C}$ were measured.

Species richness (SR) represents the numbers of species in each quadrat. All the species in the quadrats were divided into two functional groups (Allen et al., 2011): grass (grass family) and forbs (any herbaceous, dicotyledonous broad-leaved plant). The composition functional groups represent the ecological structure which contributed to the predictions of species assemblages at a more practicable and more general level, compared with the individual species. Shannon-Wiener index $(H)$ and Evenness index $(E)$ were calculated as:

Richness index $(R): R=S$;

$$
H=-\sum_{i=1}^{\infty}(P i \ln P i)
$$

Shannon-Wiener diversity index $(H)$ :

Evenness index $(E)$ :

$$
E=\frac{\bar{H}}{\ln S}
$$

where $S$ is the total species numbers of grassland community, $H$ is the Shannon-Wiener diversity index and $P i$ is the density proportion of $i$ species.

\subsection{Determination and relative calculation}

Soil water content was measured gravimetrically and expressed as a percentage of soil water to dry soil weight. Soil bulk density was calculated depending on the inner diameter of the core sampler, sampling 
depth and the oven-dried weight of the composite soil samples. Soil $\mathrm{pH}$ was measured with a glass electrode. When measuring the soil $\mathrm{pH}$, soil samples were diluted with water (the ratio of soil to water was 1:2.5). SOC was measured by the $\mathrm{K}_{2} \mathrm{Cr}_{2} \mathrm{O}_{7}$ method. Calculation of SOC:

$$
S O C=\frac{B D \times S C \times D}{10}
$$

SOC is SOC storages $\left(\mathrm{Mg} \mathrm{ha}^{-1}\right)$; BD is soil bulk density $\left(\mathrm{g} \mathrm{cm}^{-3}\right)$; $\mathrm{SC}$ is soil organic carbon concentration $\left(\mathrm{g} \mathrm{kg}^{-1}\right)$; and D is soil thickness $(\mathrm{cm})$.

Climate data were obtained based on the 1957-2005 climate data (average) of 4 weather stations in the sampling regions. All the meteorological data were obtained from the China Meteorological Data Sharing Service system.

\subsection{Data analysis}

Correlation analyses were used to determine the relationship between the meteorological features (i.e. mean annual precipitation, mean annual temperature) and plant community (cover, above-ground biomass, litter, proportion of gramineous, ShannonWiener index and species richness), as well as the relationship between below-ground biomass and SOC. Simple linear regression was used to account for the effects of environmental factors and plant community on below-ground biomass in $0-30 \mathrm{~cm}$ soil-depth. Principal Component Analysis (PCA) was applied to eliminate any redundancy among the environmental factors, biological factors and soil property variables. A variable was significantly correlated with a PC when the correlation (its loading value) with this component was at least 0.70 . A PC was considered significant when its eigenvalue was at least 1 . This stage allows us to determine the important factors in each component which affect the SOC.
To determine the specific variable impacting SOC, we conducted multiple linear stepwise regression analysis at the last stage. All statistical analysis was conducted by SPSS, ver. 18.00 (SPSS Inc, Chicago, 2009).

\section{Results}

\subsection{Effects of environmental factors on plant com- munity}

Correlation results showed that MAP positively and significantly affected plant community (Table $1, \mathrm{P}<$ 0.01 ); MAT negatively and significantly affected Cover, AGB, POG, $\mathrm{H}$ and SR $(\mathrm{P}<0.05)$ except the litter $(\mathrm{P}>0.05)$. SR is significant correlation with MAP and MAT (Table 1, P < 0.01).

Linear regression of BGB versus nine possible predictive variables showed a possible relationship with MAP, MAT, Cover, AGB, H and SR and no apparent relationships with Litter, POG and E (Figure 2). In addition, MAP, Cover, AGB, H and SR were significantly and positively correlated with BGB (Figure 2a, c, d, e, g, i, respectively). In contrast, BGB decreased with the increased MAT which can explain $18 \%$ of the variation of BGB (Figure $2 b, R^{2}=0.18$ ). BGB was mainly affected by MAP and SR $\left(R^{2}=0.30\right.$, 0.20 , respectively).

Multiple regression analysis, using as predictor variables in the environmental factors and plant community but except Litter, POG and E, showed that the MAP and $\mathrm{H}$ had significantly positive effects on BGB $\left(F=24.62, R^{2}=0.34, \mathrm{P}<0.01\right)$. The average of SOC $(1$ $\mathrm{m}$ soil depth) was $7.09 \pm 0.49$ (mean $\pm \mathrm{SE}$ ) $\mathrm{kg} \mathrm{m}^{-2}$ and plant BGB was $1.20 \pm 0.093$ (mean $\pm \mathrm{SE}$ ) $\mathrm{kg} \mathrm{m}^{-2}$ in the twenty sites (Figure 3 ). SOC showed a positive and significant relationship with $\mathrm{BGB}$, especially in $0-30$ $\mathrm{cm}$ soil depth $(\mathrm{R}=0.56, \mathrm{P}<0.01)$. There was no relationship between BGB and SOC in the $30-100 \mathrm{~cm}$ soil depth $(R=0.073, \mathrm{P}>0.05)$ 
Table 1. The relationship of meteorological features (mean annual precipitation (MAP, mm), mean annual temperature $\left(\mathrm{MAT}{ }^{\circ} \mathrm{C}\right.$, ) and plant community (cover, \%), above-ground biomass (AGB, $\mathrm{g} \mathrm{m}^{-2}$ ), litter $\left(\mathrm{g} \mathrm{m}^{-2}\right)$ the proportion of gramineous species (POG, \%), Shannon-wiener index (H), and species richness (SR)).

\begin{tabular}{lccccrr}
\hline \multirow{2}{*}{ Abiotic factors } & \multicolumn{7}{c}{ Characteristic of plant community } \\
\cline { 2 - 6 } & Cover & AGB & Litter & POG & H & SR \\
\hline MAP & $0.53^{* *}$ & $0.34^{* *}$ & $0.32^{* *}$ & $0.33^{* *}$ & $0.37^{* *}$ & $\mathbf{0 . 5 8}^{* *}$ \\
MAT & $-0.21^{*}$ & $-0.27^{* *}$ & -0.056 & $-0.37^{* *}$ & $-0.42^{* *}$ & $\mathbf{- 0 . 6 0}^{* *}$ \\
SR & $0.54^{* *}$ & $0.65^{* *}$ & 0.27 & 0.22 & $0.62^{* *}$ & 1 \\
\hline
\end{tabular}
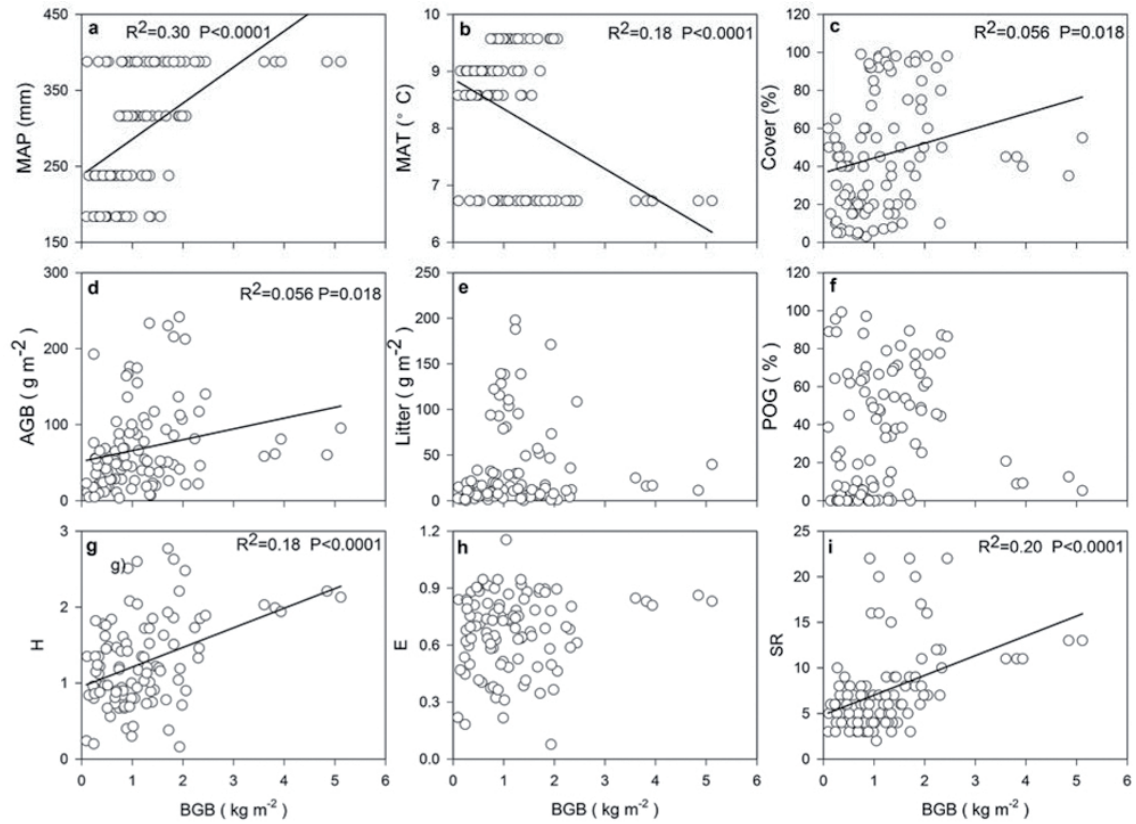

Figure 2. Linear relationship of mean annual precipitation (MAP, a), mean annual temperature (MAT, b), Cover (c), above-ground biomass (AGB, d), Litter (e), the proportion of gramineous (POG, f), Shannon-Wiener index $(\mathrm{H}, \mathrm{g})$, Evenness index (E, f) and species richness (SR, i) with below-ground biomass (BGB). 


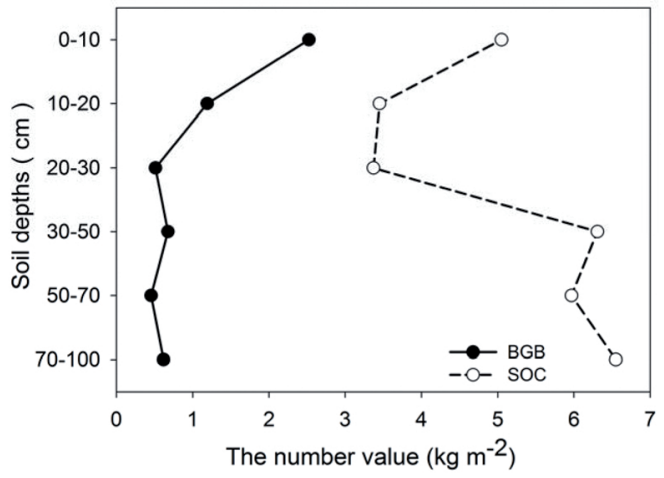

Figure 3. Changes between soil organic carbon (SOC, $\mathrm{kg} \mathrm{m}^{-2}$ ) and plant belowground biomass (BGB, $\mathrm{kg}$ $\mathrm{m}^{-2}$ ) at different soil depths in the semi-arid grassland.

\subsection{Effect of environmental factors on SOC}

The PCA results showed that the first two PCs (Comp.1 and Comp.2) explained 37.34\% and 14.41\% of the variance in the twenty sites data (Table 2).

As shown in Figure 4, SOC significantly correlated with environmental factors and biological factors ( $\mathrm{P}$ $<0.05)$. MAT, $\mathrm{R} / \mathrm{S}$ ratio, $\mathrm{BD}$ and $\mathrm{pH}$ were negatively correlated with SOC. Cover, AGB, BGB, Litter, POG, H, E, SR, SWC, MAP were positively correlated with SOC, and SOC showed stronger positively with MAP, SR and SWC.

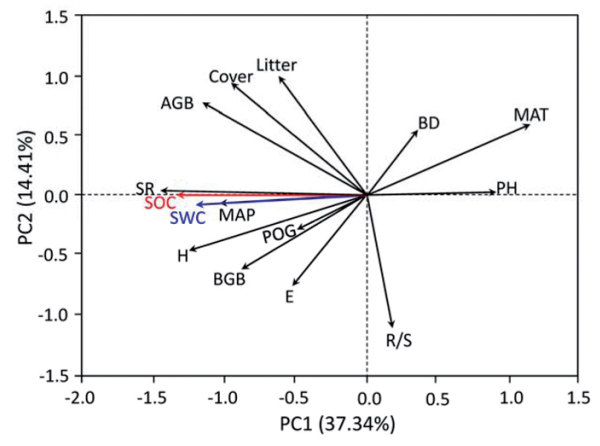

Figure 4. Biplot of the first two PCA axes of environmental factors (e.g. mean annual precipitation and mean annual temperature), biological factors (Cover, above-ground biomass, the proportion of gramineous, Shannon-Wiener index, species richness, belowground biomass, Litter, R/S ratio) and soil factors (soil $\mathrm{pH}$ value and soil water content). Abbreviations: MAT: mean annual temperature, MAP: mean annual precipitation, AGB: above-ground biomass, BGB: belowground biomass, POG: the proportion of gramineous, E: Evenness index, H: Shannon-Wiener index, SWC: soil water content, SOC: soil organic carbon.

Table 2. Eigenvalues and contribution on of principal component analysis (PCA)

Cumulative contribution rate

\begin{tabular}{cccc} 
Component & Eigenvalues & Contribution rate $(\%)$ & $(\%)$ \\
\hline 1 & 5.60 & 37.34 & 37.34 \\
2 & 2.16 & 14.41 & 51.74 \\
3 & 1.53 & 10.18 & 61.93 \\
4 & 1.45 & 9.68 & 71.61 \\
\hline
\end{tabular}




\section{Discussion}

SOC plays a critical role in controlling soil fertility and cropping system productivity and sustainability (Liu et al., 2016a). The changes in SOC were influenced by both biotic and abiotic factors whether in the agriculture, forest or grassland (Song et al., 2012; Zhou et al., 2013; Merino et al., 2015). In our study, the main abiotic factors influencing SOC were MAP and SWC, and the main biotic factors were BGB and SR. MAP and SWC changed the environment of plant growing, but the BGB and SR changed the competition of plant species in community. Greater plant species number was associated with soil $\mathrm{C}$ accumulation in $\mathrm{N}$-limited grassland communities (Tilman et al., 2006). Moreover, higher species diversity occurs in more fertile habitats without fertilizer disturbance in an alpine natural grassland community (Wu et al., 2014).

Our results showed that plant species richness had a positive relationship with soil organic carbon in the semi-arid grassland. High species richness enhanced primary productivity (Wu et al., 2011), and aboveground plant resources will be returned to the soil through decomposing in litter layers (Bardgett and Wardle, 2003). The amount of plant residuals returned to the soil affected the SOC. Below-ground biomass increased with plant species richness. Our results showed that the SOC was positively associated with root biomass in the $0-30 \mathrm{~cm}$ soil layer. The vertical distribution of SOC had a slightly stronger association with vegetation (Jobbágy and Jackson, 2000), and the root distributions affect the vertical placement of $\mathrm{C}$ in the soil. Soil $\mathrm{C}$ and $\mathrm{N}$ storage tended to increase at higher species diversity due to greater root biomass accumulation in the soil top $20 \mathrm{~cm}$ (Fornara and Tilman, 2008). The higher species richness promote greater root biomass accumulation. The increase in the $\mathrm{C}$ input from fine root enhanced organic matter protection, which also promotes SOC accumulation in the surface soil (Liu et al., 2016b). Plants regulate SOC by controlling, assimilating and accumulating $\mathrm{C}$ in the plant root system and then release from soil to atmosphere through respiration and leaching. Belowground biomass coupling with a simultaneous change in the rooting pattern would be expected to alter rhizosphere oxygen concentrations and anaerobic microbial processes (Bouchard et al., 2007). However, in the 30-100 cm soil layer, with the decrease of root biomass, there is no significant correlation was showed between BGB and SOC. There are significantly positive correlations between BGB, SWC, BGB and SWC in the soil of $0-10$ and $10-20 \mathrm{~cm}$. So higher soil water promoted more root accumulation in the top soil. BGB was not associated with SWC in the soil layer of $20-100 \mathrm{~cm}$. In this case, it is not good for root growth, and BGB was not good for SOC accumulation in the deeper soil $(30-100 \mathrm{~cm})$.

In addition, the composition of plant functional group (i.e. POG) plays an important role in affecting SOC. Meanwhile, Wu et al. (2011) has documented positive association of gramineous grass with soil nutrient properties in alpine meadow grassland. Differences in plant functional groups can create different soil biotic and abiotic microhabitats by affecting soil organic matter, soil nutrient availability, and soil microbial communities (Shang et al., 2012, 2014; Casper and Castelli, 2007). Gramineous species had higher productivity, which can result in greater amounts of nutrients fixed within their tissues (Harris et al., 2007), and a relatively higher proportion of belowground biomass (Wu et al., 2016). Gramineous species had higher belowground biomass, which is related to higher litter decomposition rate and soil nitrogen availability than that in the forbs species. Furthermore, fine roots of $\mathrm{C}_{4}$ and $\mathrm{C}_{3}$ grasses (graminoids) can contribute to an increase in the soil organic matter pool (Fornara et al., 2009). 
There was a significant negative correlation between soil $\mathrm{pH}$ and SOC. It is well known that acid deposition is a major problem to influence the ecological system (Guo et al., 2010). Acid rain causes acidification of the soil surface, and reducing soil $\mathrm{pH}$ value. Many studies showed that the soil acidification affected on the cropland and forest (Guo et al., 2010), but few studies reported the effects of soil acidification in grassland (Shi et al., 2012). Our study found SOC increased with decreased in soil $\mathrm{pH}$. This is inconsistent with the report that acidification led to a decrease in SIC, carbon stock in the topsoil would not necessarily decline with soil acidification (Guo et al., 2010). It may be partly because of that (1) acidification inhibits soil microbial activities and thus reduces the SOC decomposition rate; (2) $\mathrm{N}$ deposition, a major cause of acidification, will lead to an increase of SOC inputs with increasing vegetation productivity (Neff et al., 2002), which induce a decrease in microbial biomass and oxidase activity (Zak et al., 2008; Dalmonech et al., 2010). Therefore, low soil $\mathrm{pH}$ value may promote SOC accumulation in the semi-arid grassland.

\section{Conclusions}

We examined the effects of biotic and abiotic factors on SOC in semi-arid grassland. The results showed that MAT negatively affected on SOC and MAP positively affected on SOC. SR and the composition of plant functional group significantly affected SOC. Soil $\mathrm{pH}$ was negatively associated with SOC. Belowground biomass affected SOC mainly in the soil top $30 \mathrm{~cm}$. Our findings indicated that the main biotic factors affecting SOC are SR and belowground biomass, and the main abiotic factors affecting SOC are MAT, MAP and soil $\mathrm{pH}$ in the semi-arid grassland. We suggested that establishment of grasses-dominated artificial grassland could improve the potential sequestration of SOC in semi-arid grassland ecosystem.

\section{Acknowledgements}

This research was funded by the National Natural Science Foundation of China (31372368, 41371282), the Youth Innovation Promotion Association CAS (2011288), the "Light of West China" Program of CAS (XAB2015A04), Lanzhou Institute of Animal and Veterinary Pharmaceutics Sciences of Chinese Academy of Agricultural Sciences (CAAS-ASTIP2014-LIHPS-08).

The authors have declared no conflict of interest.

\section{References}

Allen, V., Batello, C., Berretta, E., Hodgson, J., Kothmann, M., Li, X., Mclvor, J., Milne, J., Morris, C., Peeters, A., Sanderson M.A. 2011. An international terminology for grazing lands and grazing animals. Grass Forage Sci. 66, 2-28.

Allison, S.D., Treseder, K.K. 2008. Warming and drying suppress microbial activity and carbon cycling in Boreal forest soils. Global Change Biol. 14, 2898-2909.

Bai, W.M., Wan, S.Q., Niu, S.L., Liu, W.X., Chen, Q.S., Wang, Q.B., Zhang, W.H., Han, X.G., Li, L.H. 2010. Increased temperature and precipitation interact to affect root production, mortality, and turnover in a temperate steppe: implications for ecosystem C cycling. Global Change Biol. 16, $1306-1316$

Bardgett, R.D., Wardle, D.A. 2003. Herbivore-mediated linkages between aboveground and belowground communities. Ecology. 84, 2258-2268.

Bezemer, T., Lawson, C.S., Hedlund, K., Edwards, A.R., Brook, A.J., Igual, J.M., Mortimer, S.R., van Derputten, W.H. 2006. Plant species and functional group effects on abiotic and microbial soil properties and plant-soil feedback responses in two grasslands. J. Ecol. 94, 893-904. 
Bouchard, V., Frey, S.D., Gilbert, J.M., Reed, S.E. 2007. Effects of macrophyte functional group richness on emergent freshwater wetland functions. Ecology. 88, 2903-2914.

Casper, B.B., Castelli, J.P. 2007. Evaluating plantsoil feedback together with competition in a serpentine grassland. Ecol. Lett. 10, 394-400.

Dalmonech, D., Lagomarsino, A., Moscatelli, M., Chiti, T., Valentini, R. 2010. Microbial performance under increasing nitrogen availability in a Mediterranean forest soil. Soil Biol. Biochem. 42, 1596-1606.

Fornara, D., Tilman, D. 2008. Plant functional composition influences rates of soil carbon and nitrogen accumulation. J. Ecol. 96, 314-322.

Fornara, D.A., Tilman, D., Hobbie S.E. 2009. Linkages between plant functional composition, fine root processes and potential soil $\mathrm{N}$ mineralization rates. J. Ecol. 97, 48-56.

Guo, J.H., Liu, X.J., Zhang, Y., Shen, J.L., Han, W.X., Zhang, W.F., Christie, P., Goulding, K.W.T., Vitousek, P.M., Zhang, F.S. 2010. Significant acidification in major Chinese croplands. Science. 327, 1008-1010.

Harris, W.N., Moretto, A.S., Distel, R.A., Boutton, T.W., Boo, R.M. 2007. Fire and grazing in grasslands of the Argentine Caldenal: effects on plant and soil carbon and nitrogen. Acta Oecol. 32, 207-214.

Jobbágy, E.G., Jackson, R.B. 2000. The vertical distribution of soil organic carbon and its relation to climate and vegetation. Ecol. Appl. 10, 423-436.

Kardol, P., Martijn, Bezemer, T., Van Der Putten, W.H. 2006. Temporal variation in plant-soil feedback controls succession. Ecol. Lett. 9, 1080-1088.

Liu, W.X., Zhang, Z., Wan, S.Q. 2009. Predominant role of water in regulating soil and microbial respiration and their responses to climate change in a semiarid grassland. Global Change Biol. 15, 184-195.
Liu, Y., Dang, Z.Q., Tian, F.P., Wang, D., Wu, G.L. 2016a. Soil organic carbon and inorganic carbon accumulation along a 30-year grassland restoration chronosequence in semi-arid regions (China). Land Degrad. Develop. 28: 189-198.

Liu, Y., Tian, F.P., Jia, P.Y., Zhang, J.G., and Wu, G.L. 2016b. Cultivated grasslands present a higher soil organic carbon sequestration efficiency under leguminous than under gramineous species. Solid Earth Discuss., doi:10.5194/se-2016-109.

Merino, C., Nannipieri, P., Matus, F. 2015. Soil carbon controlled by plant, microorganism and mineralogy interactions. J. Soil Sci. Plant Nutr. 15(2), 321-332.

Neff, J.C., Townsend, A.R., Gleixner, G., Lehman, S.J., Turnbull, J., Bowman, W.D. 2002. Variable effects of nitrogen additions on the stability and turnover of soil carbon. Nature. 419, 915-917.

Shang, Z.H., Cao, J.J., Guo, R.Y., Long, R.J. 2012. Effect of cultivation and abandonment on soil carbon content of sub-alpine meadows northwest China. J. Soils Sediment .12, 826-834.

Shang, Z.H., Cao, J.J., Guo, R.Y., Long, R.J., Deng, B. 2014. The response of soil organic carbon and nitrogen 10 years after returning cultivated alpine steppe to grassland by abandonment or reseeding. Catena. 119, 28-35.

Shi, Y., Baumann, F., Ma, Y., Song, C., Kühn, P., Scholten, T., He, J.S. 2012. Organic and inorganic carbon in the topsoil of the Mongolian and Tibetan grasslands: pattern, control and implications. Biogeosciences. 9, 1869-1898.

Song, B., Niu, S.L., Zhang, Z., Yang, H.J., Li, L.H., Wan, S.Q. 2012. Light and heavy fractions of soil organic matter in response to climate warming and increased precipitation in a temperate steppe. PLoS One. 7, E33217. 
Tilman, D., Hill, J., Lehman, C. 2006. Carbon-negative biofuels from low-input high-diversity grassland biomass. Science. 314,1598-1600.

Wu, G.L., Li, W., Shi, Z.H., Shangguan, Z.P. 2011. Aboveground dominant functional group predicts belowground properties in an alpine grassland community of western China. J. Soil Sediments. 11, 1011-1019.

Wu, G.L., Liu, Y., Tian, F.P., Shi, Z.H. 2016. Legumes functional group promotes soil organic carbon and nitrogen storage by increasing plant diversity. Land Degrad. Develop. doi: 10.1002/ldr.2570.

Wu, G.L., Zhang, Z.N., Wang, D., Shi, Z.H., Zhu, Y.J. 2014. Interactions of soil water content heterogeneity and species diversity patterns in semi-arid steppes on the Loess Plateau of China. J. Hydrol. $519,1362-1367$
Yang, Z., Hao, H.M., Wang, D., Chang, X.F., Zhu, Y.J., Wu, G.L. 2015. Revegetation of artificial grassland improve soil organic and inorganic carbon and water of abandoned mine. J. Soil Sci. Plant Nutr. 15, 629-638.

Zak, D.R., Holmes, W.E., Burton, A.J., Pregitzer, K.S., Talhelm, A.F. 2008. Simulated atmospheric NO ${ }^{3}$-deposition increases soil organic matter by slowing decomposition. Ecol. Appl. 18, 2016-2027.

Zhou, X.H., Talley, M., Luo, Y.Q. 2009. Biomass, litter, and soil respiration along a precipitation gradient in southern great plains, USA. Ecosystems 12, 1369-1380.

Zhou, X.Q., Chen, C.R., Wang, Y.F., Smaill, S., Clinton, P. 2013. Warming rather than increased precipitation increases soil recalcitrant organic carbon in a semiarid grassland after 6 years of treatments. PLoS One. 8, e53761. 